\title{
Comprehensive surface treatment of high-speed steel tool
}

\author{
Sergey V. Fedorov ${ }^{1, *}$, Sergey V. Aleshin ${ }^{1}$, Min Htet Swe ${ }^{1}$, Raushan D. Abdirova ${ }^{2}$, Alexey V. Kapitanov ${ }^{1}$, and \\ Sergey B. Egorov ${ }^{1}$ \\ ${ }^{1}$ MSTU "STANKIN", Vadkovsky lane, 3a, 127055 Moscow, Russia \\ ${ }^{2}$ Kazakh NTU after K.I.Satpaev, Satpaeva st. 22a, 050013 Almaty, Kazakhstan
}

Received: 10 December 2017 / Accepted: 19 December 2017

\begin{abstract}
One of the promising directions of hardening of high-speed steel tool is the creation on their surface of the layered structures with the gradient of physic-chemical properties between the wear-resistant coatings to the base material. Among the methods of such surface modification, a special process takes place based on the use of pulsed high-intensity charged particle beams. The high speed of heating and cooling allows structural-phase transformations in the surface layer, which cannot be realized in a stationary mode. The treatment was conducted in a RITM-SP unit, which constitutes a combination of a source of low-energy high-current electron beams "RITM" and two magnetron spraying systems on a single vacuum chamber. The unit enables deposition of films on the surface of the desired product and subsequent liquid-phase mixing of materials of the film and the substrate by an intense pulse electron beam. The article discusses features of the structure of the subsurface layer of high-speed steel M2, modified by surface alloying of a low-energy high-current electron beam, and its effect on the wear resistance of the tool when dry cutting hard to machine Nickel alloy. A significant decrease of intensity of wear of high-speed steel with combined treatment happens due to the displacement of the zone of wear and decrease the radius of rounding of the cutting edge because of changes in conditions of interaction with the material being treated.
\end{abstract}

Keywords: High-speed steel / surface alloying / coating / high-current electron beam / wear resistance

\section{Introduction}

Despite a year-by-year increasing usage of tools made of hard alloys, cutting ceramics and super hard materials, the quantity of high-speed steels used in the production of metal-machining tools is not decreasing at all [1,2]. Particularly, it comes to machining hard-to-machine heat-resistant nickel alloys [3,4].

During machining such alloys, there occurs an emission of a large amount of heat, the temperature level in the toolworkpiece contact zone rises drastically, which facilitates the activation of adhesion and diffusion processes and intensifies the wear of work surfaces of the tools [5-8]. It happens due to features of physical and mechanical properties thereof, as well as its cutting conditions. As a result, using hard alloys as the tool material is not always possible, and using conventional high-speed cutting tools is reasonable only at low cutting speeds [9-11]. Using modern high-speed steels with improved heat resistance obtained by powder metallurgy methods partially solves the problem of treatment intensification; however, the introduction of new construction materials with increased high-temperature

\footnotetext{
* e-mail: asv.fedorov@icloud.com
}

strength inevitably imposes additional requirements on the tool material $[12,13]$.

Nowadays, tools made of high-speed steel with various wear-resistant coatings based on refractory metal nitrides obtained by physical matter deposition are widely used. These coatings have very high micro-hardness, low friction coefficient, and are inert to machined material [14,15]. However, the practice of using coated high-speed cutting tools shows that the efficiency of such tools for different cutting operations is not uniform. The successful introduction of wear-resistant coatings is impeded by the fact that, due to a great difference in physical and mechanical properties of the substrate and the coating, there is often observed an accelerated deterioration of work surfaces of the tools during plastic deformation of the substrate under heavy loads [16-18]. This disadvantage may be dealt with by forming some transition layer which may be obtained, e.g., by performing a thermochemical treatment preceding the application of a wear-resistant coating; particularly, the ion nitriding process is used rather widely $[19,20]$. Such process is called a combined ion-plasma treatment. Its application made it possible to increase the resistance of high-speed cutting tools by several times as compared to PVD-coated tools [21,22]. 
However, it should be noted that the iron nitrides forming in the process of ion nitriding are not sufficiently thermostable, and, with the purpose to prevent the thermochemical dissociation thereof, it is necessary to limit the temperature during application of a wearresistant coating. The thermal stability of the subsurface layer of the tool, immediately adjacent to the coating, may be increased by additional surface alloying of nitride highspeed steel $[23,24]$.

The process is based on the task of reliable integration of synthesized nitride compounds of IV-V group metals and nitrogen, introduced in the steel during preliminary thermochemical treatment, in the subsurface layer of the tool. The metal is applied as a coating, e.g., using magnetron spraying. After that, an exothermic chemical reaction is initiated, which is conducted under a thermal explosion by pulse heating the surface of the product [25-27]. At that, in the capacity of reagents, a rather wide range of substances, chemically active at high temperatures, may be used [28,29]. At the same time, in the capacity of fillers and diluents, other substances may be used, including those taking part in the synthesis in the capacity of the reaction by-products. In this case, it is not the chemical nature of reagents that is of the most significance, but the magnitude of reaction heat, the heat-transfer conditions, and the kinetics of phase and structural transformations [30-32].

In this article, some interesting compositions, which may be used to obtain modified surface layers by the method considered herein to increase the durability of tools made of relatively middle-alloyed high-speed M2 steel with average heat resistance, during longitudinal turning of heat-resistant nickel alloy $\mathrm{NiCr}_{20} \mathrm{TiAl}$, are discussed.

\section{Materials and methods}

Specially-designed replaceable cutting plates (inserts) with different variants of combined surface ion-plasma treatment were used in the capacity of the cutting tool during turning operation (Fig. 1). The plates were made of highspeed M2 steel and subjected to standard salt bath heat treatment.

The nitridation of machined and ground cutting plates was performed using an APP-type unit manufactured by MSTU "STANKIN" using a two-stage vacuum-arc gas discharge [33-35]. The treatment was conducted at a temperature of $480^{\circ} \mathrm{C}$ for $30 \mathrm{~min}$, which helped create a thermochemically hardened layer having a thickness of up to $40 \mu \mathrm{m}$ and a microhardness of up to $\mathrm{HV}_{50}=115 \mathrm{MPa}$, on the surface.

The finishing wear-resistant $\mathrm{nATCRo}^{3}$ coating with a microhardness of $\mathrm{HV}_{50}=345 \mathrm{MPa}$ was applied using a

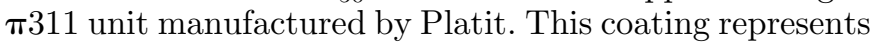
a combination of the adhesion layer of ( $\mathrm{CrTi}) \mathrm{N}$ composition, $(\mathrm{TiAl}) \mathrm{N}$ gradient coating and a multilayer nanocomposite (nc-AlTiCrN/a-Si ${ }_{3} \mathrm{~N}_{4}$ ) coating. The two-phase layer of the coating with AlTiCrN grain size of up to $5 \mathrm{~nm}$, at the boundary of which a $\mathrm{Si}_{3} \mathrm{~N}_{4}$ amorphous phase is located, suppresses the coagulation of grains of the basic phase during both the coating deposition and the tool operation. The interphase boundaries, which are the zones

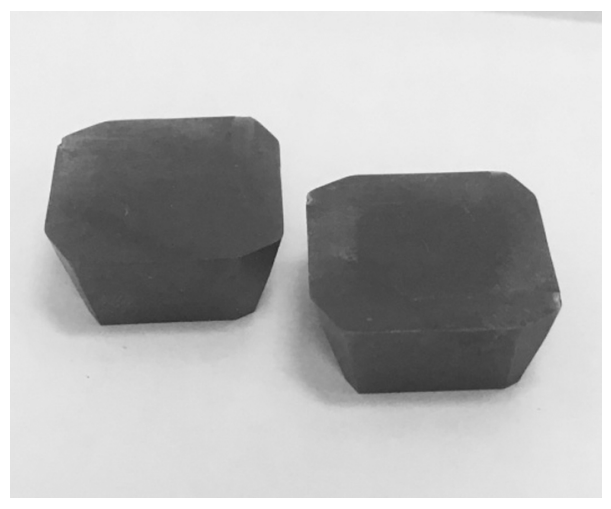

Fig. 1. Hardened cutting plates made of M2 steel.

of intense dissipation of energy, deflect the occurring cracks from the direction of spreading, slowing them down partially or entirely [36-38].

Before applying the wear-resistant coating, some of the specimens were subjected to subsurface layer alloying. The treatment was conducted in a RITM-SP Unit, which constitutes a combination of a source of low-energy highcurrent electron beams (LECHEB) "RITM", and two magnetron spraying systems on a single vacuum chamber. The unit enables deposition of films on the surface of the desired product and subsequent liquid-phase mixing of materials of the film and the substrate by an intense pulse electron beam $[39,40]$. The LEHCEB generation includes the emission of electrons, the formation of the beam in a plasma-filled diode, and the transportation thereof in a plasma channel $[41,42]$. The adoption of such generation scheme makes it possible to obtain a beam having a microsecond duration (about $5 \mu \mathrm{s}$ ) with a current density of $10^{5} \mathrm{~A} / \mathrm{cm}^{2}$, at an accelerating voltage of $15-30 \mathrm{~kW}$ [43]. At that, the area of one-time treatment amounts to about $50 \mathrm{~cm}^{2}$.

A multiphase structure using alloying during exothermic reaction occurring between the metal of the film and nitrogen was obtained by applying a thin layer of nitrideforming elements (targets made of $\mathrm{Zr}$ and $\mathrm{Nb}_{70} \mathrm{Hf}_{22} \mathrm{Ti}_{8}$ alloy was used) on the surface of the tool before treating it with an electron beam. In the capacity of donors of it, unstable iron nitrides of nitrided high-speed steel were used.

The exterior layer is enriched with refractory nitride phases, which, due to an extremely high rate of cooling, remain small and homogeneously distributed in the end product.

The depth of the subsurface layer, wherein a modified steel structure is obtained, amounts to $2-10 \mu \mathrm{m}$, depending on the alloying composition.

\section{Results and discussions}

Figure 2a shows the effect of a series of LEHCEB pulses with an energy density of $4.5 \mathrm{~J} / \mathrm{cm}^{2}$ and a duration of $5 \mu \mathrm{s}$ on the surface of nitride specimen made of M2 steel. The thermal effect of the electron beam is sufficient for the upper layer of metal to not only melt but also to begin actively evaporate, exposing the 


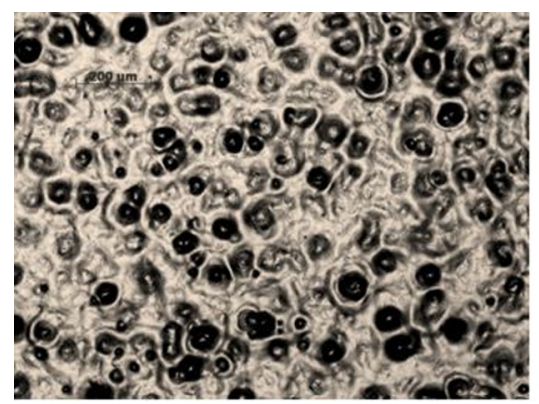

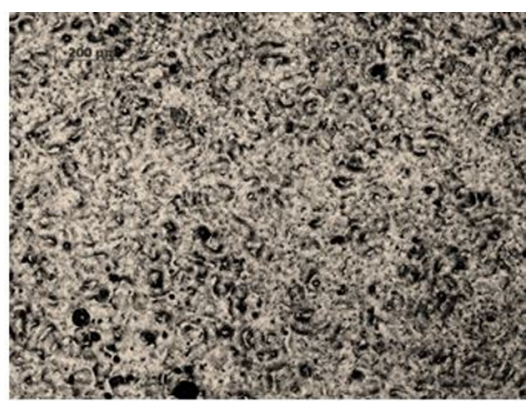

$\mathrm{b}$

Fig. 2. (a) Structure of nitride high-speed M2 steel surface after exposure to LEHCEB, (b) The same, after electron-beam zirconiumalloying.
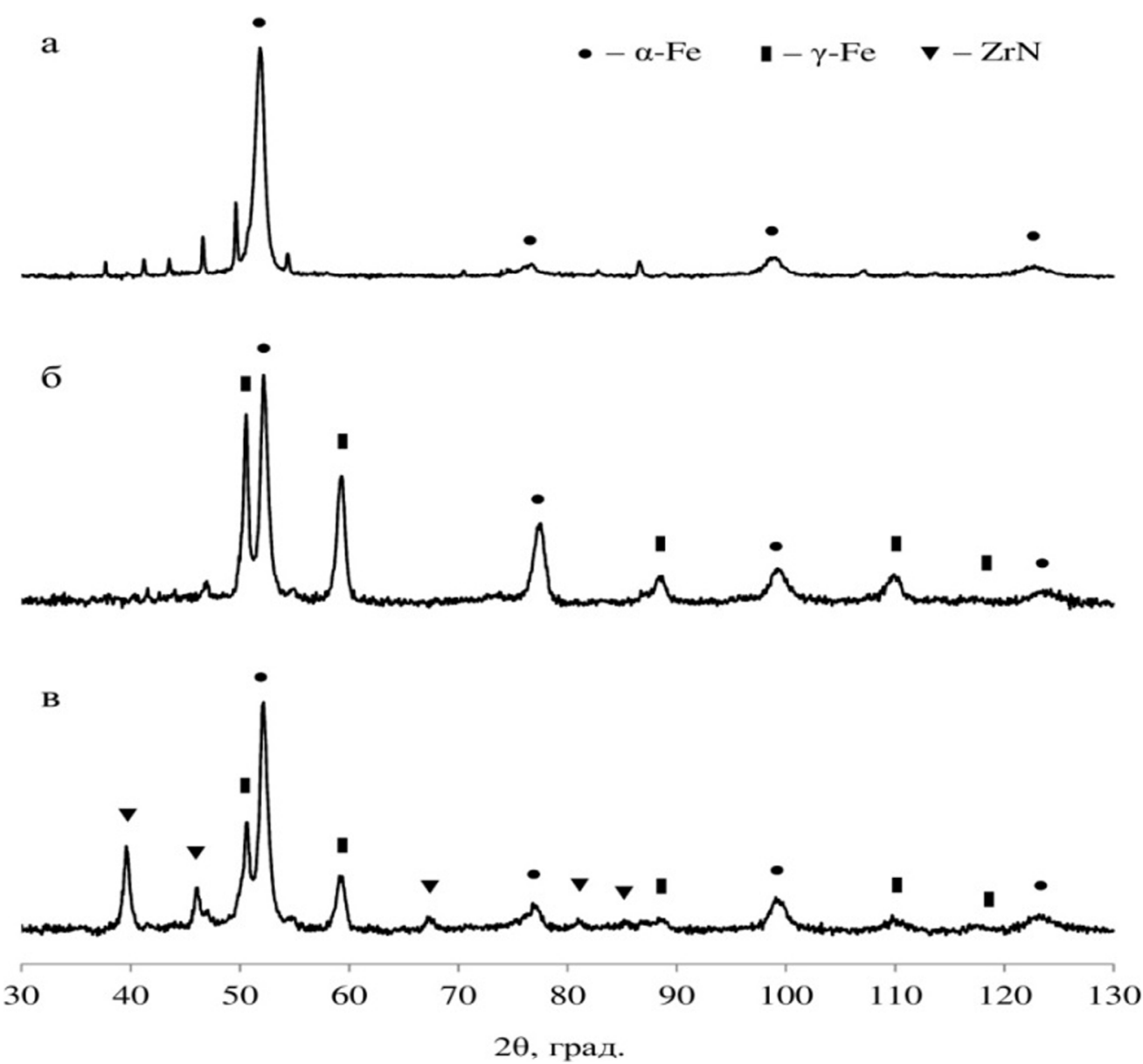

Fig. 3. (a) Diffraction pattern $(\mathrm{CoK} \alpha)$ of nitrided M2 steel specimen surface, (b) the same, after exposure to LEHCEB, (c) the same, after applying Zr coating on the surface before irradiation.

carbide constituent. The LEHCEB-irradiation causes a dissociation of iron nitrides, particularly of the $\varepsilon$-phase; a large quantity of retained austenite forms on the surface (Fig. 3b).

After applying a thin film (in this case $\mathrm{Zr}$ ) having a thickness of about $0.2 \mu \mathrm{m}$ on the specimens using a magnetron sprayer, and subsequent exposure to electron beam, it is possible to initiate exothermic chemical reactions of nitride phase formation. Due to the formation of the refractory nitride film on the surface, the evaporation of metal significantly reduces, and the structure becomes finely dispersed (Fig. 2b). The formation of nitride phase is confirmed by the data of X-ray diffraction analysis (Fig. 3c). It should be noted that in the latter case, the content of retained austenite in the subsurface layer is significantly lower. 


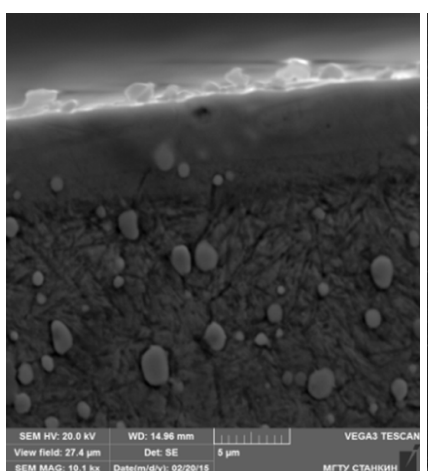

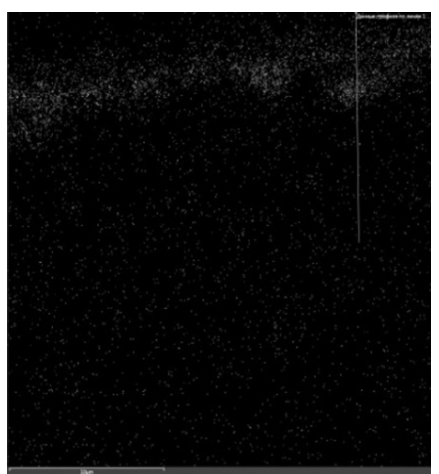

b
Fig. 4. Zirconium nitride modified subsurface layer of high-speed M2 steel. (a) SEM-image of the etched specimen, (b) map of the distribution of zirconium in the specimen.

At the same time, in our case, we are dealing with strain-hardening, caused by passing of an elastic wave, generated during pulse electron-beam exposure. However, due to a short duration of the process and to thermal inertia, the heating caused by compression and internal friction, most probably shall not be the physical factor which determines the behavior of the material in such conditions. In this case, the key role should be played by mechanical activation of high-rate physical and chemical processes, which inevitably take place both in liquid and solid phases. The appearance of the melt causes a drastic increase of the interphase surface and an increase in the rate of reaction of nitride formation, due to additional release of energy during the exothermic reaction.

Multiple initiations of the process hardly alter the initial microstructure. Typically, a series of five or six LEHCEB pulses is enough for the microalloying process to occur all the way through.

The distribution of zirconium near the surface is shown in Figure $4 \mathrm{~b}$. As is seen from this figure, $\mathrm{Zr}$ is only found in the subsurface layer with a thickness of about $2 \mu \mathrm{m}$. But the thickness of zone of influence of electron-beam treatment is $5-6 \mu \mathrm{m}$ (Fig. 4a). High-supplied energy intensity and short interaction time make it possible to expect the formation of quickly hardened layers with more uniform and finely disperse structure and improvement of performance characteristics of the subsurface layer due to the secondary hardening with the formation of the martensite-carbide structure with high hardness. Also, during the subsequent application of the wear-resistant coating, the tool is subjected to at least two hours of tempering at a temperature of $450{ }^{\circ} \mathrm{C}$, which reduces the content of retained austenite in the modified layer and facilitates residual stress relieving. A similar picture may be observed when irradiating a thin film of niobiumhafnium alloy, applied on the surface of the metal. On the diffraction pattern (Fig. 5), there appear reflections corresponding to niobium-based nitride phase.

Figure 6 shows SEM-image of a cross-section of a specimen made of M2 steel after microalloying with niobium-hafnium alloy, where a wear-resistant coating has been applied. Unlike the case of zirconium-alloying, niobium and hafnium are distributed through the entire depth of electron-beam modified subsurface layer to a depth of up to $10 \mu \mathrm{m}$ (Fig. 6b). It may be explained by the fact that the mixing of metals in the melting zone in the case of niobium alloy occurs at a higher temperature. In our case, it apparently shall be limited by evaporation temperature.

Measurements of microhardness (Fig. 7) in a crosssection show a presence of an $80 \mu \mathrm{m}$-deep hardened zone. At that, at a depth of up to $50 \mu \mathrm{m}$, the microhardness of $\mathrm{HV}_{25}$ exceeds the microhardness of the substrate by $15 \mathrm{MPa}$, and amount to about $100 \mathrm{MPa}$. The increase in the microhardness may be explained by the influence of residual tensile stresses occurring during pulse heating.

The conducted studies on wearing of the plates made of M2 steel have shown that the electron-beam alloying combined with the application of wear-resistant coating may significantly influence the tool wearing process.

The wear-resistance tests were made for turning of a heat-resistant $\mathrm{NiCr}_{20} \mathrm{TiAl}$ alloy at cutting rate $v=10 \mathrm{~m} /$ min, feed rate $s=0.115 \mathrm{~mm} / \mathrm{r}$, cutting depth $t=1 \mathrm{~mm}$. In the capacity of failure criterion, a $0.3 \mathrm{~mm}$ rear surface wear rate was chosen. Figure 8 presents the results of the study.

When cutting by an untreated tool, the characteristic location of wear emergence was the tip of the plate (Fig. 9).

It is known that the extreme wear of the back surface is caused by a gradual increase of temperature in the zone of direct contact, which in time achieves the values, at which the irreversible processes start occurring in high-speed steel. A slower wearing of back surface of the tool subjected to combined treatment, which constitutes an ion nitridation to a depth of about $40 \mu \mathrm{m}$ and subsequent application of wear-resistant coating, may be explained by the fact that the subsurface layer created under the coating has a higher hardness combined with a higher heat-resistance, and a better resistance to microplastic deformations (Fig. 10). The shape stability of the cutting edge increases, which reduces the level of internal stresses in the wear-resistant coating. Apparently, this is what slows the softening processes in the back surface.

For tools coated with the wear-resistant coating and subjected to preliminary treatment, including ion nitridation and surface alloying, there is observed a significant suppression of development of wear near the tip, which substantially delays the extreme wear stage (Fig. 11). This can be explained by the fact that the subsurface modified layer is chemically passive and reduces the adhesive interaction with the machined material. $\mathrm{Zr}, \mathrm{Ti}, \mathrm{Nb}$ and $\mathrm{Hf}$ nitrides form stable oxides. As a result, the contact process characteristics change, which significantly reduces the intensity of the source of heat emission near the cutting edge of the tool.

In case of a coated tool not subjected to microalloying, after exposure of the substrate, the friction conditions along the back surface are progressively similar to those, which are characteristic of an uncoated tool. In case of a tool subjected to a combined treatment, the modified layer continues to perform its protective functions even after the breach of the coating, which is reflected in the tool wear pattern. The combined treatment notably suppresses the formation of a worn crater on the front surface. 


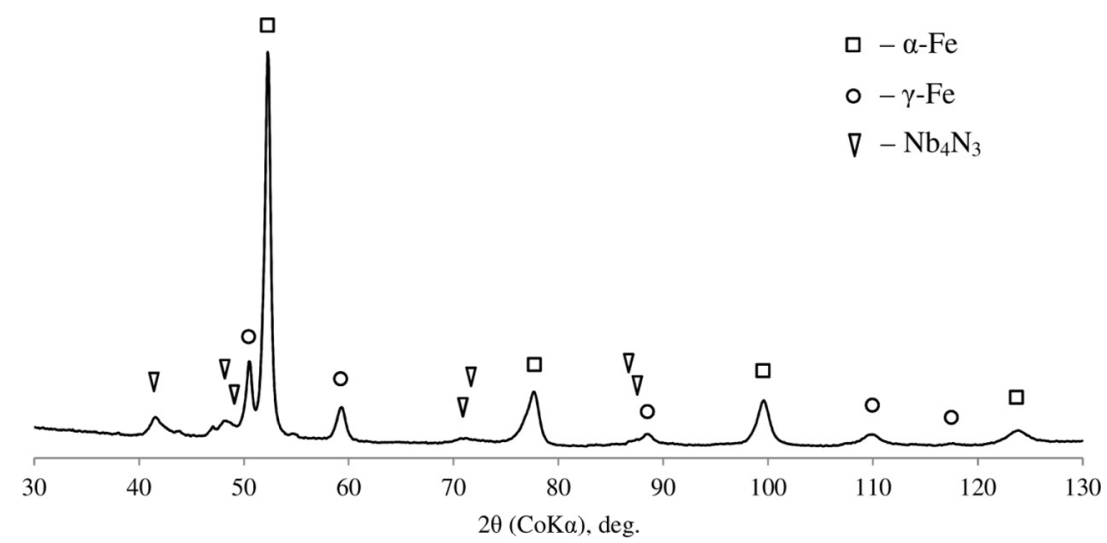

Fig. 5. Diffraction pattern $(\mathrm{CoK} \alpha)$ of nitrided M2 steel specimen surface after applying a film of NbHfTi alloy on the surface before irradiation.

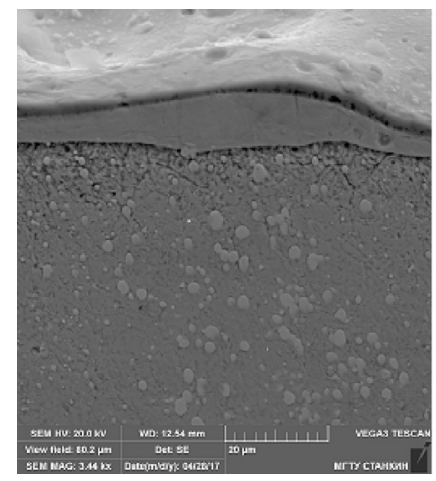

a

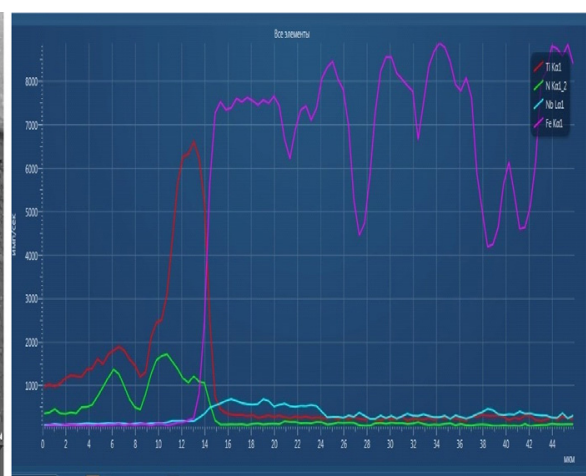

b

Fig. 6. Specimen of M2 steel after combined surface treatment: ion nitridation + microalloying of $\mathrm{Nb}_{70} \mathrm{Hf}_{22} \mathrm{Ti}_{8}$ alloys + wear-resistant nATCRo ${ }^{3}$ coating, (a) SEM-image, (b) distribution of some elements in the subsurface layer.

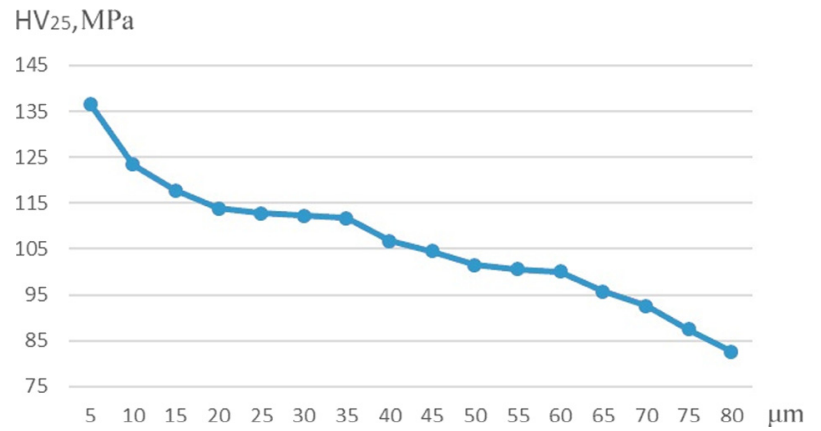

Fig. 7. Microhardness along the depth of hardened zone in the cross-section of the specimen of M2 steel after combined treatment.

At that, it should be noted that microalloying the steel with niobium-hafnium alloy produced a greater effect than microalloying it with zirconium. It confirms the fact that, in our case, the hardening of steel is mostly achieved due to the alloying of the surface layer, particularly, with niobium and hafnium nitrides, but not only due to the pulsing surface electron-beam hardening of the tool made of highspeed steel.

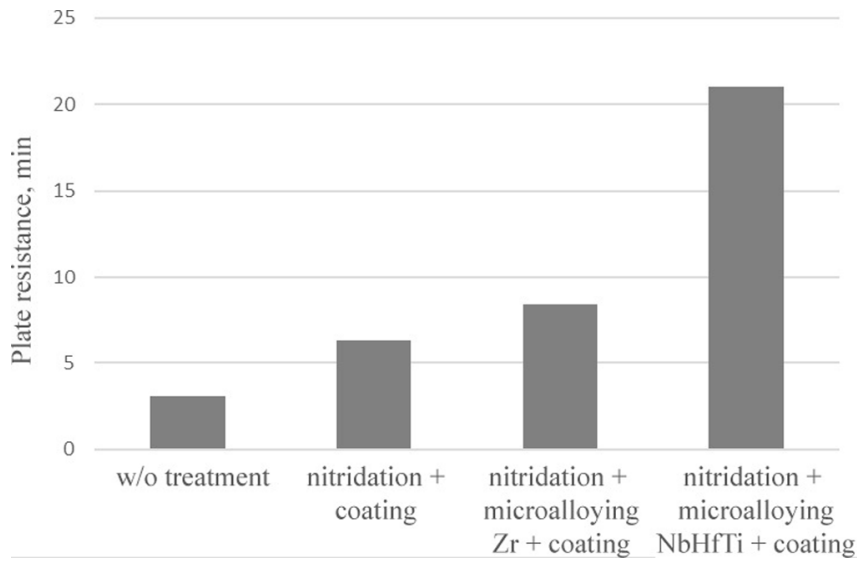

Fig. 8. Durability of plates with combined surface treatment.

It should be noted that the tool treatment time in case of surface alloying amounts to about $15 \mathrm{~min}$, without considering the vacuum degassing of the work chamber. It determines the low costs of the process and enables a full loading of middle-sized industrial machines for application of wear-resistant coatings with working cycle duration of $4-5 \mathrm{~h}$ using one surface alloying unit. 


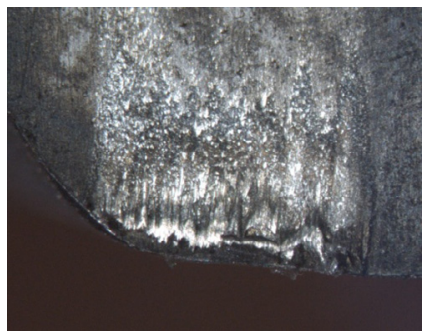

a

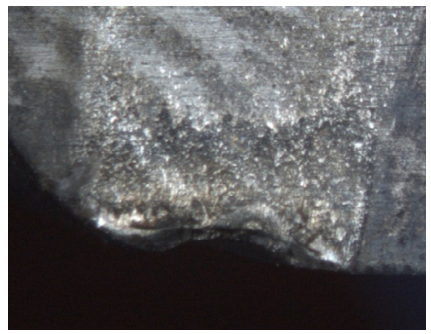

$\mathrm{b}$

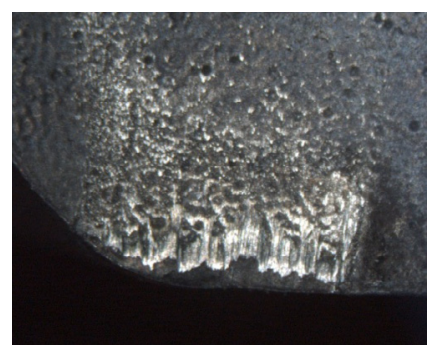

a

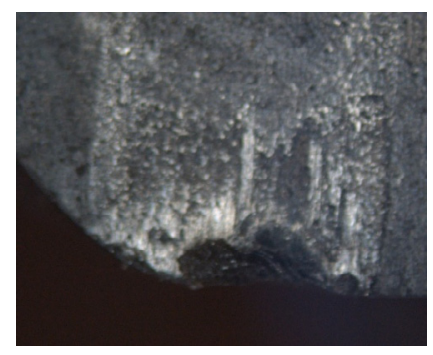

b

Fig. 9. Wear of plate made of $\mathrm{M} 2$ steel during turning of $\mathrm{NiCr}_{20} \mathrm{TiAl}$ alloy, $v=10 \mathrm{~m} / \mathrm{min}, s=0.115 \mathrm{~mm} / \mathrm{r}, t=1 \mathrm{~mm}$, a) after $1 \mathrm{~min}, \mathrm{~b})$ after $3 \mathrm{~min}$ of cutting.

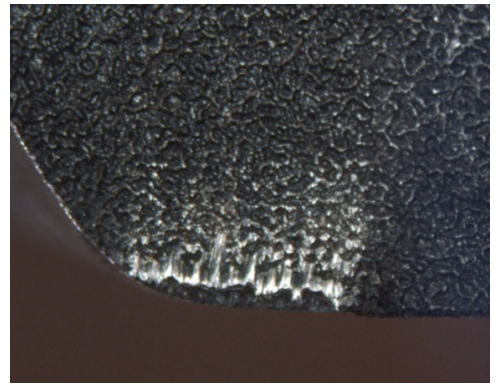

a

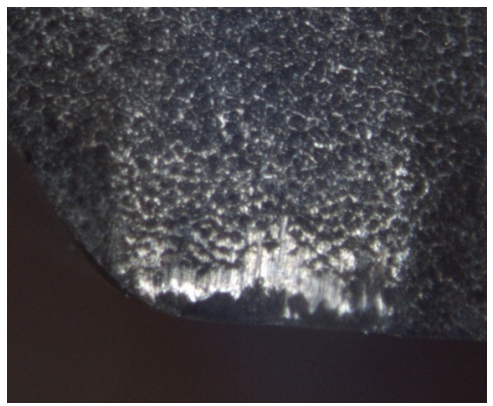

c

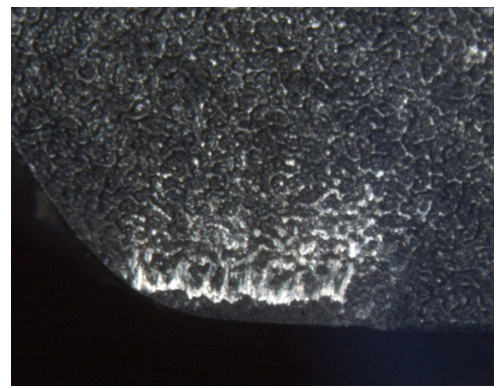

b

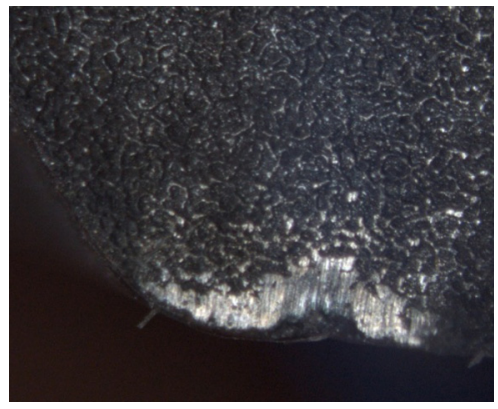

d

Fig. 11. Wear of the $\mathrm{M} 2$ steel plate (nitridation + microalloying with $\mathrm{Nb}_{70} \mathrm{Hf}_{22} \mathrm{Ti}_{8}$ alloy + coating) during turning of $\mathrm{NiCr}_{20} \mathrm{TiAl}_{\text {alloy, }}$ $v=10 \mathrm{~m} / \mathrm{min}, s=0.115 \mathrm{~mm} / \mathrm{r}, t=1 \mathrm{~mm}$, (a) after $6 \mathrm{~min}$, (b) after $10 \mathrm{~min}$, (c) after $15 \mathrm{~min}$, (d) after $21 \mathrm{~min}$ of cutting.

\section{Conclusions}

- The experimental results indicate the possibility of obtaining on the surface of the high-speed steel tool of the layers, modified by surface alloying. Such layers were obtained, thanks to the initiation of exothermic chemical reactions between substrate and deposited on it a thin film. In the reaction products was revealed the formation of new phase constituents.

- The formation of a structure in the near-surface layer of material is largely due to a pulsed nature of exposure in a microsecond range. Here, the key factors of the surface alloying process shall be represented by the energy of the electron beam, dependent on the accelerating voltage, and the thickness of the thin film applied on the surface of the object. The dependence of the thickness of a modified layer on accelerating voltage has a clear extremal character. Irradiation with insufficient energy in the beam cannot initiate a process, while the excess thereof results in evaporation of most of the film. The treatment should be performed in such a way that the thickness of coating would amount to approximately one half of depth of penetration of electrons in the substrate material, i.e., in our case, about $200 \mathrm{~nm}$.

- Microalloying may also be used. In particular, such treatment, recommended to be performed before applying the wear-resistant coating, allows to influence the wear processes of not only the high-speed but also of hard alloy cutting tools, which allows increasing the durability (in 2-3 times). 
Acknowledgements. The work was conducted with the support of the Ministry of Education and Science of the Russian Federation, in the framework of the Government Assignment No. $11.1817 .2017 / 4.6$.

The work is carried out on the equipment of the Center of collective use of MSTU "STANKIN".

\section{References}

[1] S.N. Grigoriev, Yu. A. Melnik, A.S. Metel, M.A. Volosova, Focused beams of fast neutral atoms in glow discharge plasma editors-pick, J. Appl. Phys. 121 (2017) 223302

[2] S.N. Grigoriev, T.V. Tarasova, Possibilities of the technology of additive production for making complex-shape parts and depositing functional coatings from metallic powders, Metal Sci Heat Treatment 57 (2016) 579-584

[3] O.R. Hachkevych, B.D. Drobenko, P.I. Vankevych, M. Yu. Yakovlev, Optimization of the high-temperature induction treatment modes for nonlinear electroconductive bodies, Strength Mater. 49 (2017) 429-435

[4] I. Smurov, M. Doubenskaia, S. Grigoriev, A. Nazarov, Optical Monitoring in Laser Cladding of Ti6Al4V, J. Thermal Spray Technol 21 (2012) 1357-1362

[5] S.V. Fedorov, A.A. Okunkova, N.Y. Peretyagin, P.Y. Peretyagin, Electroconductive graphene-hydroxyapatite PVD targets for magnetron sputtering, Izv. vyshih uchebnyh zaved. Fiz. 59 (2016) 192-194.

[6] M.M. Stebulyanin, A.A. Gurkina, A.A. Shein, N.Y. Cherkasova, Measuring adhesive bond strength and microhardness of multilayer composite wear-resistant coating, Mechanics \& Industry 17 (2016) 712.

[7] Q.M. Mehran, M.A. Fazal, A.R. Bushroa, S. Rubaiee, A Critical Review on Physical Vapor Deposition Coatings Applied on Different Engine Components, Crit. Rev. Solid State Mater. Sciences (2017) 1-18

[8] W.C. Guo, G. Rauchs, L. Papeleux, W.-H. Zhang, F. Gitzhofer, J.-P. Ponthot, Evaluation of the mechanical properties of plasma-sprayed coating by nanoindentation technology, Mechanics \& Industry 13 (2012) 151-162

[9] J. Zhang, Zh. Wang, M. Li, Z. Wang, T. Li, Zh. Wang, Evaluation of adhesion and mechanical properties of plasma sprayed $\mathrm{NiCrAl} / \mathrm{Al} 2 \mathrm{O} 3-13$ wt.\% TiO2 coatings, J. Adhes. Sci. Technol. (2017) 1-15

[10] S. Atlati, A. Moufki, M. Nouari, B. Haddag, Interaction between the local tribological conditions at the tool-chip interface and the thermomechanical process in the primary shear zone when dry machining the aluminum alloy AA2024-T351, Tribol. Int. 105 (2017) 326-333

[11] M.S.I. Chowdhury, S. Chowdhury, K. Yamamoto, B.D. Beake, B. Bose, A. Elfizy, D. Cavelli, G. Dosbaeva, M. Aramesh, G.S. Fox-Rabinovich, S.C. Veldhuis, Wear behaviour of coated carbide tools during machining of Ti6Al4V aerospace alloy associated with strong built up edge formation, Surf. Coat. Technol. 313 (2017) 319-327

[12] Z. Pan, Y. Feng, S.Y. Liang, Material microstructure 393 affected machining: a review, Manufacturing Rev. 4 (2017) 5

[13] M. Azadi, A.S. Rouhaghdam, S. Ahangarani, Mechanical Behavior of TiN/TiC-n Multilayer Coatings and $\operatorname{Ti}(\mathrm{C}, \mathrm{N})$ Multicomponent Coatings Produced by PACVD, Strength Mater. 8 (2016) 279-289
[14] V.V. Kuzin, M. Yu. Fedorov, M.A. Volosova, Nitride ceramic surface layer stressed state transformation with a change in TiC-coating thickness. Stress - distributed force load version. Refract. Ind. Ceram. 57 (2017) 551-556

[15] S.N. Grigoriev, Study of cutting properties and wear pattern of carbide tools with comprehensive chemical-thermal treatment and nano-structured/gradient wear-resistant coatings, Mechanics \& Industry 17 (2016) 702

[16] S.N. Grigoriev, A.S. Metel, M.A. Volosova, Y.A. Melnik, Surface hardening by means of plasma immersion ion implantation and nitriding in glow discharge with electrostatic confinement of electrons, Mechanics \& Industry 16 (2015) 711

[17] J. Tomastik, R. Ctvrtlik, Nanoscratch test - a tool for evaluation of cohesive and adhesive properties of thin films and coatings, EPJ Web Conf. 48 (2013) 00027

[18] M.M. Quazi, M. Ishak, A. Arslan, M. Nasir Bashir, I. Ali, Scratch adhesion and wear failure characteristics of PVD multilayer $\mathrm{CrTi} / \mathrm{CrTiN}$ thin film ceramic coating deposited on AA7075-T6 aerospace alloy, J. Adhes. Sci. Technol. 32 (2018) 625-641

[19] A.F.A. Trompeta, E.P. Koumoulos, I.A. Kartsonakis, C.A. Charitidis, Advanced characterization of by-product carbon film obtained by thermal chemical vapor deposition during CNT manufacturing, Manufacturing Rev. 4 (2017) 7

[20] E.V. Berlin, N.N. Koval, L.A. Seidman, Plasma thermochemical surface treatment of steel parts, Technosphera, Moscow, 2012 (in Russian).

[21] Yu.F. Ivanov, A.D. Teresov, E.A. Petrikova, O.V. Krysina, et al., Surface Alloying of SUS 321 Chromium-Nickel Steel by an Electron-Plasma Process, Russ. Phys. J. 60 (2017) 515521

[22] Y. Li, Z. Han, Y. Chen, Research on Ultrasonic Testing Methods for Adhesion Quality of Ceramic Coatings, MATEC Web Conf. 114 (2017) 02001

[23] M.A. Volosova, S.N. Grigoriev, E.A. Ostrikov, Use of laser ablation for formation of discontinuous (discrete) wearresistant coatings formed on solid carbide cutting tool by electron beam alloying and vacuum-arc deposition, Mechanics \& Industry 17 (2016) 720

[24] V. Diciuc, A. Kazek-Kesik, The structure and formation of functional hard coatings: a short review, MATEC Web Conf. 112 (2017) 04008

[25] S.N. Grigor'ev, S.V. Fedorov, M.D. Pavlov et al. Complex surface modification of carbide tool by $\mathrm{Nb}+\mathrm{Hf}+\mathrm{Ti}$ alloying followed by hardfacing $(\mathrm{Ti}+\mathrm{Al}) \mathrm{N}$, J. Frict. Wear 34 (2013) $14-18$

[26] Patent of RF No. 2015110428, Method of chemical-thermal treatment of product (Sposob himiko-termicheskoi obrabotki izdeliya)

[27] S.N. Grigoriev, S.V. Fedorov, Tool material surface alloying by wide-aperture low-energy high-current electron beam treatment before wear-resistant coating, Mechanics \& Industry 16 (2015) 708

[28] Y. Tan, F. Xi, Sh. Li, Z. Zhou, Pulse shape effects on the dynamic response of a steel beam under combined action of fire and explosionloads, J. Constr. Steel Res. 139 (2017) 484492

[29] E.A. Levashov, A S. Mukasyan, A.S. Rogachev, D.V. Shtansky. Self-propagating high-temperature synthesis of advanced materials and coatings, Int. Mater. Rev. 62 (2017) 203-239 
[30] A.S. Rogachev, S.G. Vadchenko, F. Baras, O. Politano, S. Rouvimov, et al., Combustion in reactive multilayer $\mathrm{Ni} / \mathrm{Al}$ nanofoils: experiments and molecular dynamic simulation, Combust. Flame 166 (2016) 158-169

[31] X. Cui, J. Guo, Effects of cutting parameters on tool temperatures in intermittent turning with the formation of serrated chip considered, Appl. Thermal Eng. 110 (2017) $1220-1229$

[32] J. Mu, J. Wang, Z. Zhao, Zh. Zhu, Ya. Wang, Regulating kinetics of deformation-induced phase transformation in amorphous alloy composite via tuning nano-scale compositional heterogeneity in crystalline phase, Intermetallics 93 (2017) $72-76$

[33] V.N. Gavrin, Yu. P. Kozlova, E.P. Veretenkin, A.V. Logachev, A.I. Logacheva, et al., Reactor target from metal chromium for "pure" high-intensive artificial neutrino source, Phys. Part. Nucl. Lett. 13 (2016) 267-273

[34] S.N. Grigoriev, A.S. Metel, S.V. Fedorov, Modification of the structure and properties of high-speed steel by combined vacuum-plasma treatment, Metal Sci. Heat Treat. 54 (2012) $8-12$

[35] S.N. Grigoriev, Study of cutting properties and wear pattern of carbide tools with comprehensive chemical-thermal treatment and nano-structured/gradient wear-resistant coatings, Mechanics \& Industry 17 (2016) 702

[36] V.V. Kuzin, M. Yu. Fedorov, M.A. Volosova, Nitride ceramic surface layer stressed state transformation with a change in TiC-coating thickness. Stress version - heat flow, Refract. Ind. Ceram. 58 (2017) 82-88
[37] B. Karpuschewski, J. Kundrak, T. Emmer, D. Borysenko, A New Strategy in Face Milling - Inverse Cutting Technology, Solid State Phenom. 261 (2017) 331-338

[38] M. Rief, B. Karpuschewski, E. Kalhöfer, Evaluation and modeling of the energy demand during machining, CIRP J. Manuf. Sci. Technol. 19 (2017) 62-71

[39] Ya. Wang, Zh. Yin, G. Gao, X. Zhang, Analysis of the performance of worn hydrodynamic water-lubricated plain journal bearings considering cavitation and elastic deformation, Mechanics \& Industry 18 (2017) 508

[40] L. Meisner, A. Markov, V. P. Rotshtein, et al., Microstructural characterization of Ti-Ta-based surface alloy fabricated on TiNi SMA by additive pulsed electron-beam melting of film/substrate system, J. Alloy. Compd. 730 (2017) 376-385

[41] A.B. Markov, E. V. Yakovlev, V. I. Petrov, Formation of surface alloys with a low-energy high-current electron beam for improving high-voltage hold-off of copper electrodes, IEEE Trans. Plasma Sci. 41 (2013) 2177-2182

[42] J. Cai, P. Lv, C.L. Zhang, J. Wu, Q.F. Guan, Microstructure and properties of low carbon steel after surface alloying induced by high current pulsedelectron beam, Nuclear Inst. Methods Phys. Res. Section B: Beam Interact. Mater. Atoms 410 (2017) 47-52

[43] S.V. Fedorov, M.D. Pavlov, A.A. Okunkova, Effect of structural and phase transformations in alloyed subsurface layer of hard-alloy tools on their wear resistance during cutting of high-temperature alloys, J. Frict. Wear Vol. 34 (2013) 190-198

Cite this article as: S.V. Fedorov, S.V. Aleshin, M.H. Swe, R.D. Abdirova, A.V. Kapitanov, S.B. Egorov, Comprehensive surface treatment of high-speed steel tool, Mechanics \& Industry 18, 711 (2017) 